Published in final edited form as:

Clin Obstet Gynecol. 2012 December ; 55(4): 938-944. doi:10.1097/GRF.0b013e31827146a7.

\title{
Neonatal herpes simplex virus infection
}

\author{
Thomas L. Cherpes, Dean B. Matthews, and Samantha A. Maryak \\ University of Pittsburgh School of Medicine, Department of Pediatrics, Pittsburgh, PA 15213
}

\begin{abstract}
Neonatal herpes, seen roughly in 1 of 3,000 live births in the United States, is the most serious manifestation of herpes simplex virus (HSV) infection in the perinatal period. Although acyclovir therapy decreases infant mortality associated with perinatal HSV transmission, development of permanent neurologic disabilities is not uncommon. Mother-to-neonate HSV transmission is most efficient when maternal genital tract HSV infection is acquired proximate to the time of delivery, signifying that neonatal herpes prevention strategies need to focus on decreasing the incidence of maternal infection during pregnancy and more precisely identifying infants most likely to benefit from prophylactic antiviral therapy.
\end{abstract}

\section{Keywords}

herpes simplex virus infection; humoral immunity; neonatal transmission; pregnancy

\section{Introduction}

The herpes simplex viruses (HSV-1 and HSV-2) are human pathogens that infect mucocutaneous surfaces, and can disseminate to the central nervous system (CNS) and visceral organs. More common manifestations of mucocutaneous HSV infection include gingivostomatitis, pharyngitis, keratitis, and genital ulcers. Neonatal herpes (HSV infections diagnosed within the first 28 days of birth) is diagnosed less frequently than these conditions, but is the most serious manifestation of HSV infection during pregnancy and the perinatal period. As neonatal herpes is not a reportable condition throughout the entire United States, the precise incidence of disease is difficult to determine. Retrospective studies estimate that for every 100,000 births, HSV is transmitted to as few as 10 or as many as 60 infants $[1,2]$. On the other hand, epidemiological data from the handful of individual states that mandate reporting of neonatal herpes infection, reveal incidence rates that vary between 0 to 28 cases per 100,000 births [3]. Perhaps most informative, the incidence of neonatal herpes in a large-scale prospective study conducted in Washington state was approximately 31 per 100,000 births [4], a number similar to the projected case rate of 33 per 100,000 births that was calculated using HSV-1 and HSV-2 seroprevalence data from the National Health and Nutrition Examination Survey [5].

Corresponding author: Thomas L. Cherpes, M.D., Rangos Research Center, Room 9123, 4401 Penn Avenue, Pittsburgh, PA 15224, cherpestl@upmc.edu, Phone: (412) 692-3599 Fax: (412) 692-5565.

Publisher's Disclaimer: This is a PDF file of an unedited manuscript that has been accepted for publication. As a service to our customers we are providing this early version of the manuscript. The manuscript will undergo copyediting, typesetting, and review of the resulting proof before it is published in its final citable form. Please note that during the production process errors may be discovered which could affect the content, and all legal disclaimers that apply to the journal pertain. 


\section{Maternal HSV infection}

Genital herpes, caused by HSV-1, but more frequently by HSV-2, is one of the most prevalent sexually transmitted diseases worldwide. In the United States, approximately $17 \%$ of individuals aged 14 to 49 years are thought to be HSV-2-infected, with disease prevalence significantly higher among women $(23.1 \%)$ than men (11.2\%) [6]. Although acquisition of genital herpes is often asymptomatic, systemic manifestations of first-episode primary infection may include malaise, myalgia, fever, and headache, while local manifestations may include dysuria, vaginal discharge, lymphadenopathy, and vesicular or ulcerative lesions of the external genitalia. Among women acquiring a genital herpes infection, these vesicular and ulcerative lesions most often involve the cervix, vulva, and urethra.

Both HSV-1 and HSV-2 establish latency in sacral nerve ganglia after primary genital tract infection, but HSV-2 is much more likely than HSV-1 to reactivate from this latent state and travel by anterograde transport to a genital tract mucocutaneous surface [7]. Similar to acquisition of genital herpes, most episodes of HSV reactivation and shedding in women occur in the absence of symptoms. Of note, genital tract titers of HSV found in women with no discernable genital lesions are often as high as those measured in reactivation episodes producing overt genital tract pathology [8], whilst among HSV-2 discordant couples, nearly 3 of 4 transmission events were the result of asymptomatic episodes of HSV reactivation in the source partner [9].

Because genital herpes is most often transmitted during periods of asymptomatic viral shedding, and the vast majority of neonatal herpes infections are acquired via contact with HSV-infected genital tract secretions during delivery, many investigations have sought to identify the factors promoting HSV reactivation from latency. In such studies, one of the variables found most strongly predictive of increased frequency of HSV-2 shedding in the female genital tract was recent acquisition of infection [10]. In addition, cross-sectional and longitudinal studies identified oral and injectable contraceptives use as independent risk factors for enhanced HSV genital tract shedding [11-13]. Providing corroborative support for these epidemiological investigations, our laboratory used a murine model of mucosal HSV infection to establish that medroxyprogesterone acetate and 17- $\beta$ estradiol act directly on latently infected neurons to promote HSV reactivation from latency [14, 15]. Women with a previously asymptomatic genital herpes infection were also shown more likely to experience outbreaks of symptomatic HSV reactivation during pregnancy [16], while each successive trimester of pregnancy among HSV-2-infected women correlated with more frequent genital tract shedding of the virus [17]. Taken together, these results indicate that pregnant women with recent acquisition of genital herpes infection that are exposed to dramatically elevated concentrations of serum estrogen in the last trimester of pregnancy are at especially high risk for HSV reactivation and shedding.

\section{Pathogenesis of neonatal herpes}

HSV occasionally gains access to the fetus via an ascending genital tract infection or transplacentally via chorionic villi. These in utero HSV infections can cause cataracts, pneumonitis, myocarditis, hepatosplenomegaly, chorioretinitis, encephalitis, hemolytic anemia, and growth and mental retardation. In addition to $\underline{\mathrm{H} S V}$, the wide variety of pathogens that gain access to the fetus and cause similar clinical and pathological manifestations are grouped together using the acronym "TORCH". These pathogens include Toxoplasma gondii, others (Treponema pallidum, Listeria monocytogenes, and Mycobacterium tuberculosis), rubella, and cytomegalovirus [18].

Although the overwhelming majority of neonatal herpes cases are perinatally acquired, the complex pathogenesis of this disease makes it is difficult to predict which passages through 
the maternal genital tract will result in productive infection. On the one hand, genital tract HSV reactivation frequencies sequentially increase with each trimester of pregnancy [17], and women that are shedding HSV at the time of delivery are 300 times more likely to transmit HSV infection to their newborn compared to pregnant women in whom no virus can be detected [4]. On the other hand, symptomatic genital herpes is an unreliable risk factor for neonatal HSV transmission. Among 202 pregnant women with documented shedding of HSV near the time of parturition, 74 had visible genital tract lesions but none transmitted infection to their infant [4]. Conversely, the acquisition of maternal genital tract HSV infection at or near term is a highly significant risk factor for perinatal HSV transmission. In fact, while the risk of transmission among women that have long-standing or chronic genital herpes infection is $<1 \%$, the efficiency of mother-to-neonate HSV transmission among women that acquire genital tract HSV infection in late pregnancy is considered to be at least 25\% [4]. Consequently, any woman with genital tract HSV shedding at the time of delivery that concomitantly tests negative for HSV-specific serum antibodies should be considered at higher risk for neonatal HSV transmission, as the discordancy between these two diagnostic tests is consistent with recent acquisition of maternal infection. This enhanced transmission of neonatal herpes infection among women who acquire HSV at later gestational time points may be a consequence of one or more of the following factors: 1) reduced amount of time for passive transfer of HSV-specific antibodies from mother to fetus; 2) an exposure of the neonate to elevated HSV titers in the genital tract of recently infected women as the result of cervical secretions containing lesser amounts of HSV-specific neutralizing antibodies; and 3) an increased likelihood for perinatal exposure to HSV since recent acquisition of genital herpes infection is a significant risk factor for more frequent HSV reactivation from latency and shedding $[10,13]$.

The lower binding affinity of HSV-specific antibodies initially generated by primary infection may also contribute to the higher efficiency of neonatal HSV transmission among women that acquire genital herpes infection in late pregnancy. In the humoral immune response, the ability of pathogen-specific antibodies to bind, neutralize, and eliminate microbes is lowest immediately after primary infection, but then gradually increases via a process termed affinity maturation. Early in the host response to infection, immunoglobulin heavy and light chain genes of antigen-specific B cells undergo point mutations at an exceptionally high rate, and some of these mutations will generate B cells with higher affinity for antigen. Both antigen presentation and receptor signaling from helper $\mathrm{T}$ cells promote survival of these high affinity B cells, while lower affinity B cells that recognize antigen less efficiently are eliminated by apoptosis. Thus as host defense mechanisms reduce pathogen burden, only B cells recognizing antigen with highest affinity survive, and the maturation of pathogen-specific humoral immunity manufactures immunoglobulin with higher and higher affinity for antigen [19]. Because low or absent pathogen-specific antibody affinity is more characteristic of recent primary infection, maternal HSV antibody avidity testing can be used to assess the risk of HSV transmission at delivery (avidity is a measurement of the overall strength of antigen-antibody binding, and is a function of both affinity and the valency of the interaction). Among 130 pregnant, HSV-seropositive women, $50 \%$ of the study participants with low HSV antibody avidity indexes $(<40)$ transmitted HSV to their neonate, compared to only $12 \%$ of the study participants with higher HSV antibody avidity indexes [20]. Although use of maternal HSV antibody avidity testing identified women with more recent HSV infection, and therefore at greater risk for HSV transmission, it would be less useful in the large subset of neonatal herpes infections in which maternal HSV acquisition was too recent to generate detectable levels of serum HSVspecific antibodies [20, 21].

In addition to close temporal proximity between maternal infection and parturition as a risk factor for neonatal herpes, there appears to differential efficiency of transmission between 
HSV subtypes. Through an undefined mechanism of pathogenesis, women with genital HSV-1 infection were shown to be 15 times more likely than women with genital HSV-2 infection to perinatally transmit HSV to their infant [4]. Other events shown to heighten susceptibility for neonatal HSV infection are invasive obstetrical procedures, including use of fetal scalp electrodes and delivery forceps, which disrupt neonatal epithelial barriers and expedite HSV invasion of mucocutaneous tissue [4].

\section{Clinical spectrum of neonatal herpes}

Based on clinical manifestations, neonatal herpes is classified as skin, eye, and mouth (SEM), CNS, or disseminated infections, and SEM infection now accounts for nearly half of all cases of neonatal herpes in the United States [22]. Although the majority of neonates with SEM infection develop vesicular lesions in at least 1 of these anatomic sites, $20 \%$ of the time no vesicles are seen at presentation. To categorize an infant with SEM infection, HSV, by definition, has not disseminated beyond mucocutaneous tissue, and so these infants do not present with neurologic deficits. Infants with SEM infection typically respond well to systemic acyclovir (ACV) therapy, and prognosis for normal neurological development is good [23].

CNS infection, with or without mucocutaneous involvement, accounts for another $30 \%$ of neonatal herpes cases. Although systemic ACV therapy increases the survival rate of infants with HSV CNS infection to approximately 95\%, more than half will still develop permanent neurologic disabilities, including cerebral palsy and mental retardation [24]. In the remaining 20-25\% of cases, HSV disseminates from mucocutanous surfaces to visceral organs. Even with ACV therapy, dissemination of HSV to lung, liver, and brain produces infant mortality rates approaching $30 \%$, and permanent and severe neurologic damage is frequently seen among the survivors [25]. Fortunately, ACV reduces HSV dissemination from neonatal mucocutaneous surfaces to the CNS and visceral organs, and wide-spread use of this antiviral medication in the United States in recent decades has increased the frequency with which neonatal HSV infection is confined to the skin, eyes, and oropharynx [22]. Currently, intravenous ACV (20 mg/kg) every 8 hours for 14 days is recommended for SEM infection, and this treatment regiment is extended for an additional 7 days among infants with CNS and disseminated infection [26, 27].

\section{Preventing neonatal HSV transmission}

While it seems extraordinarily obvious to advocate that clinical work-up and diagnostic testing to prevent neonatal herpes should identify mothers and infants at greatest risk for perinatal HSV transmission, the low incidence of neonatal herpes infection hinders simple determination of the most efficacious and cost-effective prevention strategies. Adding to the complexity, only about $20 \%$ of neonatal herpes cases are born to mothers with a reported history of HSV infection [28]. Despite these uncertainties, it is clear that herpetic genital tract lesions identified during pregnancy should be sampled to confirm HSV infection, and culture-based techniques and polymerase chain reaction (PCR) testing are currently available to perform this task. On the other hand, routine HSV-specific serum antibody testing to identify pregnant women with existing HSV infection may not be a practical or cost-effective prevention strategy as the risk of neonatal HSV transmission is quite low among women with chronic HSV infection, and women at greatest risk to transmit a neonatal herpes infection (i.e., those acquiring genital herpes in late pregnancy) would often test negative for HSV serum antibodies. Diagnostic testing to type HSV isolates provides further clinically relevant information, as HSV-1 reactivates from latency less frequently in the female genital tract compared to HSV-2 [7], but displays more efficient perinatal transmission [4]. When testing confirms the presence of an active recurrent genital herpes 
infection, it is currently recommended that ACV therapy to suppress HSV reactivation be offered to women who are at or beyond 36 weeks gestation [27, 29]. And in regard for the serious morbidities associated with neonatal herpes infection, cesarean delivery is also currently recommended for women with active genital HSV lesions or prodromal symptoms (e.g., vulvar pain) at the time of delivery [27].

\section{A proposed algorithm to reduce incidence of neonatal HSV infection}

Because neonatal herpes has such potentially catastrophic consequences (while the risk of neonatal herpes is dramatically higher when HSV is isolated from the maternal genital tract at the time of delivery), we close this review by advocating for validation of a management algorithm for neonatal herpes that is dependent on PCR testing to rapidly and accurately detect HSV shedding in maternal genital tract swab specimens at the time of all deliveries. This type of testing is disparate from the use of diagnostic tests to screen women for asymptomatic HSV shedding during the antepartum period, as antepartum HSV shedding does not accurately predict an infant's risk of exposure to HSV at the time of delivery [30]. Of note, a PCR assay has already been shown capable of detecting HSV DNA in genital tract specimens with exquisite sensitivity (99.6\%) and specificity (96.7\%), and was able to provide these results approximately 2 hours after specimen collection [31]. The performance characteristics determined in this study also identify PCR as strikingly superior to culturebased techniques for perinatal HSV testing, although PCR tests are not currently approved by the United States Food and Drug Administration for clinical testing of genital tract specimens [32].

Nonetheless, in this planned algorithm, we next propose that serum be obtained from all women with positive PCR test results and used for HSV-specific antibody detection and HSV antibody avidity testing. Infants from mothers whose genital tract specimens tested positive for HSV DNA, but whose serum demonstrated either undetectable levels of HSVspecific serum antibodies or low HSV avidity testing, would then prophylactically receive $\mathrm{ACV}$, as such test results would identify those infants at highest risk for neonatal herpes development. Infants whose mothers were shedding HSV but who had high HSV avidity testing, would not begin ACV prophylaxis, but instead would be carefully observed. Primary advantages of this diagnostic algorithm are that it would not incur the public health costs associated with universal serological testing of pregnant women, but would maximize the possibility that infants at highest risk for infection (i.e., from mothers who are shedding $\mathrm{HSV}$ at the time of delivery but whose serological testing suggests recent acquisition of genital herpes infection) would receive more aggressive management strategies, including ACV prophylaxis and consideration for cesarean delivery. Although the technologies needed to implement this algorithm are currently in place [20,31,33], it remains wholly untested, and obviously would require validation in clinical investigation prior to any widespread implementation.

\section{Acknowledgments}

Authors acknowledge the support for this work that was provided by the National Institutes of Health grant R56AI85110.

\section{References}

1. Gutierrez KM, Halpern MSF, Maldonado Y, Arvin AM. The epidemiology of neonatal herpes simplex virus in California from 1985 to 1995. J Infect Dis. 1999; 180:199-202. [PubMed: 10353880]

2. Whitley R, Davis EA, Suppapanya N. Incidence of neonatal herpes simplex virus infections in a managed-care population. Sex Transm Dis. 2007; 34:704-708. [PubMed: 17413535] 
3. Dinh T-H, Dunne EF, Markowitz LE, Weinstock H, Berman S. Assessing neonatal herpes reporting in the United States, 2000-2005. Sex Transm Dis. 2008; 35:19-21. [PubMed: 18157062]

4. Brown ZA, Wald A, Morrow RA, Selke S, Zeh J, Corey L. Effect of serologic status and cesarean delivery on transmission rates of herpes simplex virus from mother to infant. JAMA. 2003; 289:203-209. [PubMed: 12517231]

5. Xu F, Markowitz LE, Gottlieb SL, Berman SM. Seroprevalence of herpes simplex virus types 1 and 2 in pregnant women in the United States. Am J Obstet Gynecol. 2007; 196:43.e1-43.e6. [PubMed: 17240228]

6. Xu F, Sternberg MR, Kottiri BJ, et al. Trends in herpes simplex virus type 1 and type 2 seroprevalence in the United States. JAMA. 2006; 296:964-973. [PubMed: 16926356]

7. Benedetti J, Corey L, Ashley R. Recurrence rates in genital herpes after symptomatic first-episode infection. Ann Intern Med. 1994; 121:847-854. [PubMed: 7978697]

8. Wald A, Corey L, Cone R, Hobson A, Davis G, Zeh J. Frequent genital herpes simplex virus 2 shedding in immunocompetent women. Effect of acyclovir treatment. J Clin Invest. 1997; 99:10921097. [PubMed: 9062368]

9. Mertz GJ, Benedetti J, Ashley R, Selke SA, Corey L. Risk factors for the sexual transmission of genital herpes. Ann Intern Med. 1992; 116:197-202. [PubMed: 1309413]

10. Wald A, Zeh J, Selke S, Ashley RA, Corey L. Virologic characteristics of subclinical and asymptomatic genital herpes infections. Ann Intern Med. 1995; 333:770-775.

11. Mostad SB, Kreiss JK, Ryncarz AJ, Mandaliya K, Chohan B, Ndinya-Achola J, Bwayo JJ, Corey $\mathrm{L}$, et al. Cervical shedding of herpes simplex virus in human immunodeficiency virus-infected women: Effects of hormonal contraception, pregnancy, and vitamin A deficiency. J Infect Dis. 2000; 181:58-63. [PubMed: 10608751]

12. Mostad SB, Overbaugh J, DeVange DM, et al. Hormonal contraception, vitamin A deficiency, and other risk factors for shedding of HIV-1 infected cells from the cervix and vagina. Lancet. 1997; 350:922-927. [PubMed: 9314871]

13. Cherpes TL, Melan MA, Kant JA, et al. Genital tract shedding of herpes simplex virus type 2 in women: effects of hormonal contraception, bacterial vaginosis, and vaginal Group B Streptococcus colonization. Clin Infect Dis. 2005; 40:1422-1428. [PubMed: 15844064]

14. Cherpes TL, Busch JL, Sheridan BS, Harvey SA, Hendricks RL. Medroxyprogesterone acetate inhibits CD8+ T cell viral specific effector function and induces herpes simplex virus type 1 reactivation. J Immunol. 2008; 181:969-975. [PubMed: 18606648]

15. Vicetti Miguel RD, Sheridan BS, Harvey SA, Hendricks RL, Cherpes TL. 17- $\beta$ estradiol promotion of herpes simplex virus type 1 reactivation is estrogen-receptor dependent. J Virol. 2010; 84:565-572. [PubMed: 19846508]

16. Frenkel LM, Garratty EM, Shen JP, Wheeler N, Clark O, Bryson YJ. Clinical reactivation of herpes simplex virus type 2 infection in seropositive pregnant women with no history of genital herpes. Ann Intern Med. 1993; 118:414-418. [PubMed: 8439114]

17. Brown ZA, Vontver LA, Benedetti J, et al. Genital herpes in pregnancy: risk factors associated with recurrences and asymptomatic viral shedding. Am J Obstet Gynecol. 1985; 153:24-30. [PubMed: 2994477]

18. Del Pizzo J. Focus on diagnosis: congenital infections (TORCH). Pediatr Rev. 2011; 32:537-542. [PubMed: 22135424]

19. Hangartner L, Zinkernagel RM, Hengartner H. Antiviral antibody responses: the two extremes of a wide spectrum. Nat Rev Immunol. 2006; 6:231-243. [PubMed: 16498452]

20. Brown EL, Morrow R, Krantz EM, et al. Maternal herpes simplex virus antibody avidity and risk of neonatal herpes. Am J Obstet Gynecol. 2006; 195:115-120. [PubMed: 16813750]

21. Lindsay MK. HSV neutralizing antibodies further refinement in preventing neonatal Herpes infection. Am J Obstet Gynecol. 2006; 195:4-6. [PubMed: 16813741]

22. Kimberlin DW, Lin CY, Jacobs RF, et al. Natural history of neonatal herpes simplex virus infections in the acyclovir era. Pediatrics. 2001; 108:223-229. [PubMed: 11483781]

23. Kimberlin DW, Lin CY, Jacobs RF, et al. Safety and efficacy of high-dose intravenous acyclovir in the management of neonatal herpes simplex virus infections. Pediatrics. 2001; 108:230-238. [PubMed: 11483782] 
24. Engman ML, Adolfsson I, Lewensohn-Fuchs I, et al. Neuropsychologic outcomes in children with neonatal herpes encephalitis. Pediatr Neurol. 2008; 38:398-405. [PubMed: 18486821]

25. Kimberlin DW. Herpes simplex virus infections in neonates and early childhood. Semin Pediatr Infect Dis. 2005; 16:271-281. [PubMed: 16210107]

26. Pickering, LK. Red Book, 2009: the report of the Committee on Infectious Diseases. Elk Grove Village, IL: American Academy of Pediatrics; 2009. Herpes simplex; p. 363-373.

27. ACOG Practice Bulletin. Clinical management guidelines for obstetricians-gynecologists. No. 82 June 2007. Management of herpes in pregnancy. Obstet Gynecol. 2007; 109:1489-1498. [PubMed: 17569194]

28. Whitley RJ, Corey L, Arvin A, et al. Changing presentation of herpes simplex virus infections in neonates. J Infect Dis. 1988; 158:109-116. [PubMed: 3392410]

29. Corey L, Wald A. Maternal and neonatal herpes simplex virus infections. N Engl J Med. 2009; 361:1376-1385. [PubMed: 19797284]

30. Arvin AM, Hensleigh PA, Prober CG, et al. Failure of antepartum maternal cultures to predict the infant's risk of exposure to herpes simplex virus at delivery. N Engl J Med. 1986; 315:796-800. [PubMed: 3018565]

31. Gardella C, Huang ML, Wald A, et al. Rapid polymerase chain reaction assay to detect herpes simplex virus in the genital tract of women in labor. Obstet Gynecol. 2010; 115:1209-1216. [PubMed: 20502292]

32. Sexually transmitted diseases treatment guidelines. Centers for Disease Control and Prevention MMWR Recomm Rep. 2006; 55:1-94.

33. Gardella C, Brown Z. Prevention of neonatal herpes. BJOG. 2011; 118:187-192. [PubMed: 21159118] 